\title{
Isotope Dilution Mass Spectrometry
}

National Cancer Institute

\section{Source}

National Cancer Institute. Isotope Dilution Mass Spectrometry. NCI Thesaurus. Code C99492.

A mass spectrometry technique used to increase the precision and accuracy of chemical analysis. A known amount of an enriched isotope of the element of interest is added to the sample and acts as an internal standard. 